\title{
Brown Tumor due to Vitamin D Deficiency in a Child with Cerebral Palsy
}

\author{
Jaivinder Yadav • Priyanka Madaan • Vandana Jain
}

Received: 1 March 2014 / Accepted: 12 June 2014 / Published online: 29 June 2014

(C) Dr. K C Chaudhuri Foundation 2014

To the Editor: Children with disabilities are predisposed to deficiency of various macro- and micro-nutrients due to factors such as feeding difficulties, dietary restrictions, immobility, dependency, neglect, and pubertal delay. Here we share our experience of a child with cerebral palsy who presented with brown tumor of the jaw due to nutritional vitamin D deficiency $[1,2]$.

A 12-y-old child with cerebral palsy presented with complaints of swelling of jaws and difficulty in chewing for the past 18 mo. He had two episodes of seizures two months prior, with documented hypocalcemia requiring intravenous calcium. On examination, his jaws were abnormally prominent but with bony consistency and no tenderness. He also had rachitic rosary, wrist widening, genu varum, double malleoli and multiple joint contractures. The child was severely malnourished, stunted, prepubertal and diet was deficient in calories and protein by $\sim 30 \mathrm{~g}$.

He had low serum calcium and phosphate $(7.5$ and $2.8 \mathrm{mg} /$ $\mathrm{dl}$, respectively) with extremely high alkaline phosphatase (ALP) $(13,331 \mathrm{U} / \mathrm{L}), 25$ hydroxyvitamin $\mathrm{D}$ in insufficient range (25 OHD) $(22 \mathrm{ng} / \mathrm{ml}$ after receiving 60,000 U outside) parathormone (PTH) level $(1,459 \mathrm{pg} / \mathrm{ml})$. USG neck and $\mathrm{Tc}^{99}$ Sestamibi scan revealed normal sized parathyroid glands. Skeletal survey showed changes of rickets and lytic lesions. Biopsy of the jaw lesion was suggestive of brown tumor. Based on these investigations, a diagnosis of long standing severe nutritional vitamin D deficiency with secondary hyperparathyroidism resulting in brown tumor was

J. Yadav $\cdot$ V. Jain $(\bowtie)$

Division of Pediatric Endocrinology, Department of Pediatrics, All India Institute of Medical Sciences, New Delhi 110029, India e-mail: drvandanajain@gmail.com

\section{P. Madaan}

Department of Pediatrics, All India Institute of Medical Sciences, New Delhi, India made. The child was treated with 6 lakh units of 25 OHD, repeat radiograph showed healing line, PTH and ALP decreased to $57.7 \mathrm{pg} / \mathrm{ml}$ and $296 \mathrm{U} / \mathrm{L}$ respectively and 25 OHD rose to $97 \mathrm{ng} / \mathrm{ml}$.

Brown tumor results from excessive osteoclastic activity (stimulated by PTH) with formation of osteolytic cysts that subsequently get filled by hemosiderin. Brown tumors are generally seen in patients with primary or tertiary hyperparathyroidism, and in patients with renal osteodystrophy. Severe vitamin $\mathrm{D}$ deficiency with brown tumor formation is extremely rare $[3,4]$.

Above experience highlights the importance of nutritional rehabilitation in addition to physical rehabilitation in improving the quality of life in children with cerebral palsy. Micronutrient status should ideally be assessed biochemically at regular intervals and replenished before the appearance of clinical symptoms [5].

Conflict of Interest None.

Source of Funding None.

\section{References}

1. Munns CFJ, Cowell CT. Prevention and treatment of osteoporosis in chronically ill children. J Musculoskelet Neuronal Interact. 2005;5: 262-72.

2. Zacharin M. Current advances in bone health of disabled children. Curr Opin Pediatr. 2004;16:545-51.

3. Arunkumar KV, Kumar S, Deepa D. Brown tumor in mandible as a first sign of vitamin D deficiency: a rare case report and review. Indian J Endocr Metab. 2012;16:310-5.

4. Bereket A, Casur Y, Firat P, Yordam N. Brown tumour as a complication of secondary hyperparathyroidism in severe long lasting vitamin D deficiency rickets. Eur J Pediatr. 2000;159:70-3.

5. Schoendorfer N, Boyd R, Davies PS. Micronutrient adequacy and morbidity: paucity of information in children with cerebral palsy. Nutr Rev. 2010;68:739-48. 